\title{
Pengaruh Pelayanan Pemuda Berbasis Kontekstual Terhadap Pertumbuhan Gereja Kemah Injil Indonesia di Kota Samarinda
}

\section{The Effect of Contextual Based Youth Services on the Growth of the Gereja Kemah Injil Indonesia in Samarinda City}

\author{
Robi Panggarra ${ }^{1)^{*}}$, Leonard Sumule ${ }^{2)}$ \\ 1) Prodi Ilmu Filsafat Sekolah Tinggi Filsafat Jaffray Makassar, Indonesia \\ 2) Alumnus Biola University, California, United State of America \\ *Penulis korespondensi: robi.panggarra@sttjaffray.ac.id
}

Received: 29 December 2018/Revised: 15 February 2019 /Accepted: 31 March 2019

\begin{abstract}
Abstrak
Masalah yang dihadapi gereja-gereja hari ini adalah berkurangnya minat kaum muda terhadap kegiatan gereja. Gereja perlu mengevaluasi pelayanan pemuda yang sudah dilaksanakan selama ini, untuk dapat melihat tingkat keefektifan setiap kegiatan yang dilakukan untuk dapat menjangkau generasi muda. Tujuan penelitian ini adalah untuk mengetahui pengaruh pelayanan pemuda yang berbasis kontekstual terhadap pertumbuhan Gereja Kemah Injil Indonesia di Kota Samarinda. Penulis menggunakan metode analisis linear berganda untuk melihat pengaruh pelayananan pemuda berbasis kontekstual terhadap pertumbuhan gereja. Setelah melakukan penelitian, ditemukan bahwa ada pengaruh yang signifikan antara pelayanan pemuda berbasis kontekstual terhadap pertumbuhan kuantitas Gereja Kemah Injil Indonesia di Kota Samarinda. Pelayanan pemuda yang berbasis kontekstual adalah sebuah jawaban yang perlu dipertimbangakan agar gereja dapat melaksanakan pelayanan yang relevan dengan kehidupan kaum muda modern yang hidup dalam culture kemajuan informasi digital yang sangat cepat. Pelayanan pemuda yang berbasis kontekstual dapat membantu pelayanan gereja menjadi efektif bagi pengjangkauan generasi milenial.
\end{abstract}

Kata-kata kunci: pelayanan, pemuda, kontekstual, pertumbuhan, gereja

\section{Abstract}

The problem with churches today is the reduced interest of young people in church activities. The church needs to evaluate the youth ministry that has been doing, so the church can see the effectiveness of each event they 
did to reach young people. The purpose of this research is to find out the influence of youth-based contextual services to the growth of Gereja Kemah Injil Indonesia in Samarinda City. To achieve this, the author uses the method of multiple linear analysis to see the effect of contextual youth services on church growth. After conducting research, it was found that there was a significant influence between contextual youth services on the growth of the quantity of the Gereja Kemah Injil Indonesia in Samarinda City. Contextual based youth ministry is an answer that needs to be considered so the church can provide services that are relevant to the lives of modern young people who live in their particular culture. On the other side, contextual based youth ministry to help church services be useful for reaching the millennial generation.

Keywords: service, youth, contextual, growth, church

\section{Pendahuluan}

Pelayanan kepada kelompok kaum muda merupakan suatu pelayanan yang sungguh-sungguh penting. Hal tersebut dikarenakan kaum muda adalah generasi yang disebutkan sebagai masa depan bangsa, masa depan gereja, dan masa depan keluarga. Menurut Suzanne dan Ben, "Orang muda adalah aktor kunci dalam sebagian besar proses ekonomi dan sosial." Bram Aloysius Widyanto kemudian menegaskan pula bahwa "Berdasar pada sejarah, pemuda merupakan unsur yang menarik dan esensial dalam suatu gerakan perubahan, maka menarik untuk dikaji. ... Bersama pemuda, kapal yang bernama Indonesia akan ditentukan maju, diam atau tenggelam." ${ }^{2}$ Berdasarkan kedua kutipan di atas, jelas bahwa pelayanan generasi muda merupakan sesuatu yang benar-benar urgent sehingga perlu mendapat perhatian yang serius dan terfokus.

Selanjutnya, Ann Grinnell dalam bukunya menuliskan bahwa "Kehidupan orang muda di zaman sekarang seperti perahu yang melewati sungai besar dalam keadaan gelap. Mereka tidak tahu jalan serta pilihan yang benar dan untuk menjamin masa depan mereka. ${ }^{3}$ Mereka menghadapi kehidupan tanpa memiliki kepastian arah yang pasti. Mereka

${ }^{1}$ Suzanne Naafs dan Ben White, "Generasi Antara: Refleksi tentang Studi

Pemuda Indonesia,” Jurnal Studi Pemuda I, no. 2 (September 2012):90, https://journal.ugm.ac.id/jurnalpemuda/article/viewFile/32063/19387

2 Aloysius Bram Widyanto, "Pemuda Dalam Perubahan Sosial," Jurnal Historia Vitae 24, No. 2 (Oktober 2010): 153-162,

https://www.usd.ac.id/lembaga/lppm/fll3/Jurnal\%20Historia\%20Vitae/vol24no2oktob er2010/PEMUDA\%20DALAM\%20PERUBAHAN\%20SOSIAL\%20bram\%20widyanto. pdf 2011), 13

${ }^{3}$ Ann Grinnell, Dream Big, Start Small (Jakarta: Depatemen Pemuda GKII dan CMA, 
perlu ditolong menyadari bahwa mereka memikul harapan banyak kepentingan di masa depan, dan karenanya perlu dipertimbangkan sebagai suatu tanggung jawab yang perlu disikapi dan dipersiapkan secara sengaja dan matang.

Pelayanan pemuda sudah menjadi pelayanan kategorial dari gerejagereja yang ada di Samarinda, namun berdasarkan pengamatan dan informasi pra penelitian, ditemukan bahwa pelayanan pemuda yang ada belum menghasilkan suatu capaian yang maksimal dalam kaitannya dengan pertumbuhan gereja. Gereja masih sangat terbatas pada mengorganisir pelayanan ibadah pemuda di gereja, dan masih kurang memerhatikan berbagai pendekatan pelayanan yang dapat dilakukan sesuai dengan konteks pemuda masa kini.

Oleh sebab itu, gereja mulai memikirkan pelayanan yang dapat menjangkau kaum muda secara utuh, di mana mereka akan merasa dihargai, dikasihi, dibutuhkan, dan sekaligus harapan masa depan gereja, dan bangsa. Pelayanan di mana gereja memasuki dunia, dan kebudayaan mereka tanpa curiga, dan tanpa justifikasi yang terlalu dini, sebagai suatu upaya untuk membangun jembatan untuk menciptakan suatu hubungan yang alami namun arahnya jelas menuju pertemanan rohani. Pelayanan ini tidak lain adalah pelayanan pemuda yang berbasis kontekstual. Pelayanan yang akan mampu membawa anak-anak muda untuk mengalami Kristus secara nyata melalui kesiapan gereja atau orang-orang dewasa yang ingin membagikan hidup, waktu, dan perhatian mereka kepada kelompok kaum muda tersebut. Pelayanan kaum muda yang berbasis kontekstual adalah sebuah jawaban yang dapat menolong gereja untuk membangun hubungan yang berhasil dengan kaum muda, tetapi sekaligus akan membuat gereja mengalami pertumbuhan secara kuantitas. Dengan demikian, fokus utama dalam tulisan ini adalah bagaimana pengaruh pelayanan pemuda yang berbasis kontekstual terhadap pertumbuhan Gereja Kemah Injil Indonesia Kota Samarinda?

\section{Kajian Teori}

\section{Pelayanan Kaum Muda yang Berbasis Kontekstualisasi}

Perlu disadari bahwa dunia dalam perkembangannya selalu mengalami perubahan. Meninggalkan era primitif dan memasuki era teknologi yang serba canggih, dunia mengalami perkembangan yang semakin pesat. Perkembangan pesat itu pun terjadi dengan sangat cepat, sehingga dalam waktu yang relatif singkat dapat memengaruhi seluruh aspek kehidupan umat manusia. Hal itu tidak hanya menyangkut perkembangan teknologi dunia dalam hal ilmu pengetahuan yang tentu masih merupakan aspek yang sangat luas, karena nantinya akan terbagi 
ke dalam berbagai disiplin ilmu. Akan tetapi, hal itu juga berpengaruh kepada kelompok usia dalam masyarakat termasuk kaum muda.

Kata pelayanan dalam bagian ini dimaknai sebagai yang dimaksud dalam oleh Thayer dalam bukunya: "diakonia yaitu service, ministering, esp. of those who execute the commands of others; 2. of those who by the command of God proclaim and promote religion among men." ${ }^{4}$ Kata pelayanan yang dimaksudkan dikaitkan dengan pekerjaan melayani yang dilakukan oleh orang-orang tertentu dalam rangka melakukan perintah Allah untuk memberitakan ajaran agamanya kepada orang lain. Pelayanan dalam hal ini dimaksudkan sebagai upaya gereja dalam melaksanakan kegiatan-kegiatan yang melibatkan kelompok kaum muda baik bagi pemuda gereja yang aktif maupun juga kepada mereka yang kurang bahkan tidak aktif agar mereka bisa dijangkau.

Kata kontekstual secara umum berarti penyesuaian dengan konteks atau ruang lingkup tertentu. Kata ini sendiri telah mengalami penyesuaian dalam pemakaiannya, termasuk sering dikaitkan dengan teologi. Dalam kaitannya dengan kontekstualisasi teologi, Bevans mengartikan itu sebagai "Upaya untuk memahami iman Kristen dipandang dari segi suatu konteks tertentu." Kontekstual dalam hal ini dipahami sebagai situasi tertentu dari suatu konteks. Dengan demikian, bagi Bevans iman Kristen dapat saja memiliki praktek yang berbeda di suatu tempat tertentu daripada tempat lainnya. Menurut A. Scott Moreau, "Contextualization can be described as the process whereby Christian adapt the forms, content, and praxis of the Christian faith so as to communicate to the mind and hearts of people with other cultural backgrounds." ${ }^{6}$ Memerhatikan definisi Moreau, kekristenan dituntut untuk dapat menyesuaikan diri dengan baik dari segi bentuk, isi, dan praksis iman terhadap berbagai latar belakang budaya lain. Ditinjau secara teologis maka "kontekstualisasi adalah proses di mana wahyu Allah tentang siapa Dia, dan tujuan kekal-Nya dikomunikasikan, dipahami, dan dihayati dengan cara-cara yang bermakna oleh budaya yang terikat dan kelompok-kelompok kemanusiaan yang beragam secara budaya."7

4 Joseph H. Thayer, Thayer's Greek-English Lexicon of the New Testament (Massachusetts: Hendrikckson Publishers, 2007), 137. 2002), 1 .

${ }^{5}$ Stephen B. Bevans, Model-Model Teologi Kontekstual (Maumere: Penerbit Ledalero,

${ }^{6}$ A. Scott Moreau, Contextualization in World Missions: Mapping and Assessing Evangelical Models (Grand Rapids: Kregel Publications, 2016), 36.

${ }^{7}$ Michael Andrew Manna, "The Indigenous Contextialization Model Ukrainian Youth Ministers' Adaptation of Practical Theological Education” (Biola University, 2015), 3, http://www.youthdiscipler.com/uploads/8/0/1/9/8019280/manna__the_indigenous_contextualization_model.pdf.; D. Hayward, "Lecture notes on contextualization (printed handout)," (Biola University extension, Klaipeda, Lithuania, 2006). 
Jika dikaitkan dengan pelayanan yang kontekstual, maka pelayanan kontekstual dapat diartikan sebagai pelayanan yang memerhatikan unsur budaya setempat sebagai jembatan komunikasi yang efektif terhadap pikiran dan hati orang lain. Pelayanan kontekstual harus memerhatikan unsur budaya lokal dari setiap orang yang dilayani, refleksi ideal sesuai dengan konteks lokal, dan berfokus pada komunikasi yang dipahami oleh pikiran dan hati. Churchill mendefinisikan budaya adalah di mana dan bagaimana orang mengembangkan identitas mereka, dan itu harus dihormati dan dihormati, terutama dalam program pemuda. ${ }^{8}$ Program pemuda menjadi bermanfaat bila mereka terlibat, dan berpartisipasi aktif. Program pemuda bermanfaat selama pemuda terlibat dan berpartisipasi aktif. Memiliki keterlibatan dan partisipasi ini akan membantu dalam pengembangan maksimal untuk pemuda, seperti "orang muda seperti mereka yang berada di tahun-tahun pertengahan lebih mungkin untuk mencapai yang diinginkan hasil perkembangan ketika mereka secara aktif terlibat dalam pembelajaran dan pengembangan mereka sendiri." ${ }^{\prime}$

\section{Pendekatan Pelayanan Pemuda yang Berbasis Kontekstual}

Penulis buku Everything Twentys dalam bukunya menyatakan bahwa: "We have a responsibility as people of faith to look for opportunities to serve others. ${ }^{10}$ Kutipan ini secara jelas memberikan indikasi tentang tanggung jawab orang percaya untuk mencari peluang agar dapat melayani orang lain (dalam hal ini tentu termasuk juga melayani anak-anak muda). Jika demikian, maka hal itu seharusnya merupakan suatu pekerjaan serius yang perlu dipikirkan, direncanakan, dan dilaksanakan secara konsisten dalam rangka mencari peluang untuk menjangkau anak-anak muda. Pelayanan ini harus mempertimbangkan berbagai konteks kehidupan kaum muda, agar pelayanan yang dilakukan dapat sesuai dengan kebutuhan kaum muda. Pelayanan itu harus berusaha "menghapuskan pandangan bahwa gereja itu membosankan." ${ }^{\prime \prime}$ Ada beberapa sarana atau media untuk melakukan kontekstualisasi dalam pelayanan pemuda

${ }^{8}$ Dana Churchill, Cultural Contextualization Recommendations for Latino Youth Programs, Master of Arts, International Community Development (South Africa: Northwest University, 2016), 9 , https://archives.northwestu.edu/bitstream/handle/nu/25177/churchill_dana_icd_2016.p df?sequence $=1$.

9 Joyce A. Walker, "Intentional Youth Programs: Taking Theory to Practice." New Directions for Youth Development (2006): 76.

${ }^{10}$ David Edwards et al., Everything Twentys (Illinois: Tyndale house publishers, $7^{\text {th }}$ edition 2011), 128.

${ }^{11}$ Doug Fields, Purpose Driven Youth Ministry: 9 Landasan Penting Bagi Pertumbuhan yang Sehat (Malang: Gandum Mas, 2014), 151. 
seperti musik dan multimedia, olahraga, komunitas, dan kelompok kecil dalam gereja, dan masyarakat.

\section{Musik dan Sarana Multimedia dalam Ibadah yang Kontekstual}

Bagi kelompok anak muda modern, apalagi bagi mereka yang tinggal daerah perkotaan, musik merupakan sesuatu yang sudah tak terpisahkan dari aktivitas keseharian mereka. Hal tersebut merupakan kebutuhan yang selalu menemani perjalanan mereka. Entah pada waktu makan, belajar mandiri, berada di rumah ataupun di ruang publik, ciri kelompok ini selalu terlihat jelas dengan earphone yang selalu melekat di telinga mereka. Kecanggihan teknologi smartphone menambah vitur videomax juga membuat mereka semakin mudah menikmati fasilitas hiburan di mana saja dan kapan saja.

Mempertimbangkan kebiasaan yang sudah terbangun sebagai budaya mereka, maka pelayanan kaum muda yang ingin berhasil perlu memerhatikan unsur-unsur tersebut dalam menyiapkan pelayanan ibadah pemuda di gereja. Gereja-gereja sudah perlu memerhatikan ketersediaan fasilitas alat musik dalam sarana multimedia lainnya untuk ibadah kaum muda. Belum lagi jika mengingat bahwa Alkitab sendiri juga sangat banyak berbicara tentang musik dalam ibadah (2 Taw. 5:11-14).

Musik dalam ibadah seperti combo band, akan memberi nuansa ibadah tersendiri kepada kaum muda. Tanpa bermaksud meremehkan musik tradisional, namun kaum muda modern tentu lebih menyukai bentuk-bentuk alat musik modern pula. Doug Fields menyebutkan bahwa: Sebelum kaum muda dan remaja merasa nyaman dengan lingkungan, mereka tidak akan sadar dengan hal-hal teologis. Karena itu, perlu membuat suatu lingkungan positif dengan berbagai cara, dan salah satunya adalah memainkan musik kontemporer. ${ }^{12}$ Oleh sebab itu, gerejagereja kota perlu memerhatikan penyediaan fasilitas alat musik yang memadai jika mereka ingin gereja mereka dikunjungi oleh kaum muda. Demikian juga perlu memiliki sarana penunjang fasilitas multimedia, seperti: komputer atau laptop, dan LCD.

Beberapa manfaat yang diharapkan dari pendekatan ini, adalah: pertama, ketersediaan alat musik dapat mengiring pujian dalam ibadah, sehingga mengarahkan setiap orang untuk senang bernyanyi sesuai dengan nada yang dimainkan dari alat musik. Bagian ini akan dihubungkan dengan variabel pertumbuhan gereja secara kualitas. Kedua, alat musik membuat suasana ibadah menjadi hidup dan bersemangat. Bagian ini akan dihubungkan dengan variabel pertumbuhan gereja secara kualitas. Ketiga, ketersediaan sarana multimedia memungkinkan untuk

12 Doug Fields, Purpose Driven Youth Ministry: 9 Landasan Penting Bagi Pertumbuhanyang Sehat (Malang: Gandum Mas, 2014), 153. 
menayangkan syair lagu yang dinyanyikan, sehingga bagi mereka yang tidak atau belum menghafal lagunya, bisa ikut bernyanyi. Bagian ini akan dihubungkan dengan variabel pertumbuhan gereja secara kualitas. Keempat, saranan multimedia dapat digunakan untuk menayangkan video clip, bahkan full video untuk menayangkan film-film rohani menjadi tontonan kaum muda, sekaligus menjadi variasi kegiatan ibadah. Bagian ini akan dihubungkan dengan variabel pertumbuhan gereja secara kualitas.

Adapun tujuan yang diharapkan dari penyediaan sarana musik dan multimedia ialah sebagai berikut: pertama, meningkatkan minat atau ketertarikan kaum muda untuk menghadiri ibadah. Bagian ini akan dihubungkan variabel pertumbuhan secara kuantitas. Kedua, memberikan kesempatan keterlibatan kaum muda dalam pelayanan. Bagian ini akan dihubungkan dengan variabel pertumbuhan secara kuantitas. Ketiga, menjaga konsentrasi kaum muda terfokus kepada ibadah. Bagian ini akan dihubungkan dengan variabel pertumbuhan gereja secara kualitas. Keempat, menjauhkan rasa bosan atau kejenuhan saat mengikuti ibadah. Bagian ini akan dihubungkan dengan variabel pertumbuhan gereja secara kuantitas.

\section{Olahraga untuk Penjangkauan yang Kontekstual}

Salah satu hobi yang sangat banyak disukai kelompok kaum muda adalah kegiatan olahraga. Mulai dari permainan bola voli, basket, sepak bola, futsal, badminton, renang, dan lain sebagainya, selalu saja bentukbentuk olahraga ini menarik minat paling besar dari kalangan kaum muda. Hal tersebut segera terlihat ketika mengunjungi gedung olahraga atau pusat-pusat kegiatan olahraga, di mana presentasi pengunjung atau pemain terbesar biasanya adalah kaum muda. Pertanyaannya Doug Fields adalah: Apakah anda memiliki suatu program di mana kaum muda dan remaja anda bisa merasa nyaman untuk mengajak teman-teman mereka yang belum percaya? Jika anda memilikinya, program-program tersebut melibatkan baik mereka yag sudah Kristen maupun non-Kristen. ${ }^{13}$

Dari kutipan di atas, jelas bahwa Doug mencoba mengajukan suatu pertanyaan yang menggelitik gereja mengenai program apa yang mereka miliki yang dapat melibatkan kaum muda di dalamnya. Keterlibatan tersebut bahkan tidak terbatas hanya kepada pemuda Kristen saja, melainkan bisa saja juga melibatkan yang non-Kristen. Oleh sebab itu, olahraga dapat saja menjadi salah satu program gereja yang khusus disiapkan untuk penjangkauan yang umum bagi kelompok pemuda.

${ }^{13}$ Doug Fields, Purpose Driven Youth Ministry: 9 Landasan Penting Bagi Pertumbuhanyang Sehat (Malang: Gandum Mas, 2014), 150. 
Dalam hal penjangkauan kaum muda yang banyak menyukai kegiatan olahraga, diharapkan bahwa:

Pertama, olahraga dapat menjadi jembatan penghubung untuk dapat bertemu dan berkenalan dengan kaum muda. Bagian ini akan dihubungkan dengan pertumbuhan gereja secara kuantitas.

Kedua, terciptanya hubungan pertemanan melalui olahraga dapat memberikan akses komunikasi yang lebih luas sampai kepada hal-hal yang bersifat pribadi. Bagian ini akan dihubungkan dengan pertumbuhan gereja secara kuantitas.

Ketiga, jika sudah terjadi hubungan yang akrab dan komunikasi yang intens, maka diharapkan ada peluang untuk sampai kepada komunikasi rohani. Bagian ini akan dihubungkan dengan pertumbuhan gereja secara kuantitas. Dalam pelaksanaannya, gereja dapat menentukan salah satu atau beberapa kegiatan olahraga yang akan menjadi sarana pengjangkauan. Langkah kedua, adalah melakukan observasi ke lapangan untuk menentukan lokasi mana yang akan dipilih. Ketiga, mulailah membuat jadwal yang disesuaikan dengan jadwal kebanyakan kaum muda ada dan berkumpul di sana. Keempat, dekati mereka dengan ramah dan mulailah memperkenalkan diri. Kelima, ajaklah mereka untuk berolahraga bersama. Keenam, buat janji temu untuk olahraga selanjutnya (dapatkan alamat atau nomor hpnya). Ketujuh, mulailah kirim pesan untuk mengingatkan janji olahraga bersama (buat kesan persahabatan yang hangat dan akrab). Kedelapan, ciptakan komunikasi yang hangat selama berolahraga dengan mencoba untuk menyelidik lebih lanjut tentang kegiatan kesehariannya, tentang latar belakang keluarganya, dll (tujuannya agar dapat memperoleh informasi sebanyak mungkin mengenai pribadinya, serta dapat menciptakan komunikasi yang lebih sesuai dengan kebutuhannya ke depan). Kesembilan, cari tahu lewat komunikasi, apakah dia memiliki pergumulan atau masalah (hal tersebut dapat menjadi jembatan untuk menawarkan pertolongan atau menjadikan persahabatan menjadi semakin nyata dan semakin dekat). Kesepuluh, pada tahap komunikasi yang sudah saling percaya dan terbuka, bisa ditingkatkan kepada percakapan rohani. Hal ini akan memimpin pembicaraan kepada informasi apakah orangnya sudah mengenal Yesus secara pribadi atau belum. Jika belum, maka itu akan menjadi peluang untuk dapat melihat kesempatan baik untuk mengabarkan Injil kepadanya.

\section{Komunitas Sebagai Persekutuan yang Kontekstual}

Kebanyakan kelompok kaum muda memiliki komunitas khusus yang menghubungkan mereka dengan teman-teman sebaya. Mark H. Senter III mengatakan bahwa: 
Pertemuan-pertemuan kaum muda memberikan kesempatan untuk menjalankan dua fungsi dalam model komunitas. Di satu pihak, hal itu menjadi sarana peremuan bagi teman-teman Kristen (fungsi sosiologis), dan pihak lain, memberikan suatu konteks di mana tata nilai Kristen dapat disuguhkan melalui diskusi dan perdebatan (fungsi stimulasi). ${ }^{14}$

Komunitas itu juga menjadi kelompok yang menyatukan mereka dalam menyalurkan minat yang sama secara bersama-sama. Misalnya, komunitas motor, mobil, travelling, camping, nonton bareng, menyanyi, olahraga, dan sebagainya.

Kebutuhan akan komunitas biasanya sangat terasa bagi kehidupan orang muda, oleh karena kebutuhan sosial dan aktualisasi diri. Mereka perlu pengakuan orang lain, serta rasa nyaman karena diterima oleh kelompok dan orang lain. Doug Fields ingin menekankan hal ini dengan mengajukan pertanyaan: "Kapan terakhir kali anda bersama sekelompok orang dan tidak mengenal siapa pun? Bagaimana perasaan anda? Karena kita sering merasa nyaman dalam ibadah kita, kita sering lupa bagaimana sakitnya sendirian itu."15 Untuk menghindarkan hal seperti ini dalam persekutuan, maka perlu adanya persekutuan (komunitas) yang dititikberatkan pada memberikan perhatian yang cukup bagi setiap orang yang hadir dalam komunitas persekutuan itu. Akibatnya, komunitas biasanya menjadi rumah yang nyaman bagi setiap kaum muda, serta rumah yang untuknya mereka rela berkorban untuk menjaga kelestrariannya. Sebelumnya juga sudah dijelaskan bahwa ada kalanya kaum muda lebih memilih komunitas mereka disbanding keluarga sendiri yang di dalamnya mereka kurang merasa nyaman.

Memerhatikan kebutuhan kaum muda akan komunitas, maka pelayanan gereja melalui komunitas merupakan salah bentuk persekutuan yang kontekstual. Tujuannya adalah: pertama, agar pemuda dapat merasa lebih nyaman oleh karena mereka dilayani namun tidak tercabut dari komunitas. Bagian ini akan dihubungkan dengan variabel pertumbuhan gereja secara kuantitas. Kedua, pelayanan melalui komunitas membuat pemuda merasa kurang tekanan, oleh karena suasana yang tidak terlalu formal. Bagian ini akan dihubungkan dengan variabel pertumbuhan gereja secara kuantitas. Ketiga, pelayanan melalui komunitas akan meningkatkan suasana kekeluargaan bagi kaum muda. Bagian ini akan dihubungkan dengan variabel pertumbuhan gereja secara kuantitas.

${ }^{14}$ Warren Benson \& Mark H. Senter III, Pedoman Lengkap Untuk Pelayanan Kaum Muda jilid 2 (Bandung: Kalam Hidup, 1999), 68.

${ }^{15}$ Doug Fields, Purpose Driven Youth Ministry: 9 Landasan Penting Bagi Pertumbuhan yang Sehat (Malang: Gandum Mas, 2014), 155. 
Kelompok Kecil Sebagai Pemuridan yang Kontekstual

Sebagaimana telah dijelaskan di atas, kaum muda senang dengan komunitas atau kelompok. Karena kaum muda senang dengan komunitas atau kelompok, maka dalam melaksanakan pelayanan pemuridan kepada kaum muda, perlu mempertimbangkan unsur kesukaan atau suasana yang cocok dengan budaya dan kebiasaan mereka. Memerhatikan alasan tersebut, maka pemuridan kelompok kaum muda juga akan lebih baik dilakukan melalui pendekatan kelompok. "Kelompok kecil adalah jawaban jangka panjang bagi besarnya budaya kita." ${ }^{16}$ Kelompok ini akan dibentuk dengan tujuan untuk memuridkan kaum muda di dalamnya. Oleh karena itu, kelompok ini disebut sebagai kelompok kecil (bisa saja ada nama yang khusus). Kelompok kecil pendalaman Alkitab mungkin saja adalah konsep umum yang sudah biasa dipahami dalam gereja. Namun pendekatan kelompok kecil adalah pendekatan yang sesuai dengan kebiasaan kaum muda.

Tujuan pelaksanaan kelompok kecil adalah: pertama, agar pemuda dapat belajar Alkitab secara kreatif. Bagian ini akan dihubungkan dengan variabel pertumbuhan gereja secara kualitas. Kedua, pemuda dapat belajar Alkitab dalam suasana yang aktif (bukan hanya pasif seperti di ibadah raya). Bagian ini akan dihubungkan dengan variabel pertumbuhan gereja secara kualitas. Ketiga, pemuda dapat belajar Alkitab dengan menyenangkan (sesuai dengan kelompok usia, ada permainan/ice breaker untuk mengurangi ketegangan dalam kelompok). Bagian ini akan dihubungkan dengan variabel pertumbuhan gereja secara kualitas.

Jika demikian, bagaimana kelompok kecil akan dilakukan: Pertama, Welcome yang berisi sambutan hangat kepada semua peserta sehingga merasa nyaman dan diterima. Selain itu dapat dimainkan beberapa permainan yang menolong untuk mencairkan suasana dan membina keakraban sesama anggota kelompok. Doug Fields berkata: "Banyak kaum muda dan remaja senang menjadi bagian dari sekumpulan orang, tetapi ketika harus memilih antara menjadi orang yang tidak dikenal dalam sekumpulan orang dan menjadi dikenal dalam sebuah kelompok kecil, mereka akan selalu memilih yang terakhir."17 Kedua, Worship yaitu menyanyikan beberapa lagu dan akhirnya berdoa untuk mempersiapkan diri masuk dalam pelajaran Alkitab. Ketiga, Word yaitu waktu yang dikhususkan untuk belajar Alkitab. Pembelajaran ini dapat dilakukan dengan pemimpin mulai menentukan bacaan Alkitab (cara membaca bisa

${ }^{16}$ Doug Fields, Purpose Driven Youth Ministry: 9 Landasan Penting Bagi Pertumbuhanyang Sehat (Malang: Gandum Mas, 2014), 178.

${ }^{17}$ Doug Fields, Purpose Driven Youth Ministry: 9 Landasan Penting Bagi Pertumbuhan yang Sehat (Malang: Gandum Mas, 2014), 181. 
bervariasi: bertanggapan, membaca bersama, membaca pribadi). Selanjutnya pemimpin akan mengajukan beberapa pertanyaan pedoman atau acuan lalu memberikan kesempatan kepada setiap orang untuk berbicara atau menyampaikan pendapatnya. Salah satu tujuan kelompok kecil adalah "membuat kaum muda dan remaja berbicara."18 Pada bagian akhir, pemimpin akan menutup dengan konklusi yang menyenangkan dan mudah diingat. Keempat, Work yaitu bagian dari perencanaan pertemuan berikut, berbagi pokok doa dan saling mendoakan sebelum berpisah. Ini melengkapi tujuan kelompok kecil, yaitu "membuat kaum muda dan remaja menerapkan iman mereka."19 Untuk menambah suasana semakin menyenangkan, pemimpin dapat menyiapkan snack untuk dinikmati secara bersama sambil membina keakraban.

\section{Metode}

Metode penelitian kuantitatif dengan menggunakan angket untuk melihat sebab akibat dalam penelitian. Data-data yang diperoleh diolah dengan analisis regresi linear berganda dengan menggunakan estimasi Ordinary Least Squares. ${ }^{20}$ Analisis regresi linier adalah teknik statistik untuk memodelkan hubungan linear antara dua atau lebih banyak variabel. Ini digunakan untuk menjelaskan hubungan antara variabel dependen, dan dua atau lebih variabel independen sedemikian rupa sehingga perilaku variabel dependen dapat diprediksi dari variabel independen jika hubungannya ada. ${ }^{21}$ Dalam penelitian ini, penulis menggunakan pendekatan kuantitatif dengan mementingkan adanya variabel-variabel sebagai objek penelitian dan variabel-variabel tersebut harus didefinisikan dalam bentuk operasionalisasi masing-masing. Hal ini dipilih mengingat bahwa: "Dasar yang paling tepat untuk melaksanakan penelitian uji adalah eksperimen yang bertujuan meneliti hubungan antara sebab dan akibat."22 Dengan demikian, hal ini sesuai dengan maksud penulis untuk mencoba menemukan hubungan sebab akibat antara pelayanan pemuda yang berbasis kontekstual terhadap pertumbuhan gereja (GKII) di daerah kota Samarinda.

${ }^{18}$ Doug Fields, Purpose Driven Youth Ministry: 9 Landasan Penting Bagi Pertumbuhan yang Sehat (Malang: Gandum Mas, 2014), 182.

${ }^{19}$ Fields, 182.

${ }^{20}$ Hengky Latan, Selva Temalagi, Analisis multivariate teknik dan aplikasi menggunakan program IBM SPSS 20.0 (Bandung: Alfabeta, 2013).

${ }^{21}$ N. M. Egbo and D. C. Bartholomew, "Forecasting Students' Enrollment Using Neural Networks and Ordinary Least Squares Regression Models," Journal of Advanced Statistics 3, no. 4 (December 1, 2018): 49.s

22 J. Vredenbregt, Metode dan Teknik Penelitian Masyarakat (Jakarta: Gramedia, 1984), 34. 
Data-data yang diperoleh selanjutnya dinalisis menggunakan analisis regresi linear berganda. Menurut Latan, dan Temalangi, "Metode regresi dengan menggunakan estimasi Ordinary Least Squares (OLS) merupakan teknik statistik yang paling popular digunakan dalam penelitian empiris." ${ }^{23}$ Tujuan dalam metode ini adalah untuk mengetahui pengaruh satu atau lebih variabel independen terhadap satu variabel dependen.

Rumus $^{24}$

$\mathrm{Y}=\mathrm{b} 0+\mathrm{blXl}+\mathrm{b} 2 \mathrm{X} 2+\mathrm{bX} 3+\mathrm{bX} 4+\mathrm{bkXk}+\mathrm{e}$

Keterangan:

$\mathrm{Y}=$ Variabel dependen

$\mathrm{X}=$ variabel independen

b0 bl b2 b3 b4 bk = koefisien-koefisien variabel independen $\mathrm{e}=$ error

Sebagaimana telah dijelaskan sebelumnya, maka indikatorindikator variabel $X$ dalam jurnal ini dibedakan atas Xl= musik dan sarana multimedia, $\mathrm{X} 2=$ olahraga untuk penjangkauan, $\mathrm{X} 3=$ Komunitas, dan $\mathrm{X} 4=$ Kelompok kecil; sedangkan indikator variabel $\mathrm{Y}$ yang dimaksudkan adalah indikator pertumbuhan secara kuantitas atau jumlah. Data-data yang diperoleh melalui angket, kemudian dianalisis menggunakan program SPSS 22.

\section{Hasil dan Pembahasan}

\section{Pengaruh Pelayanan Pemuda Berbasis Kontekstual Terhadap} Pertumbuhan Gereja Kemah Injil Indonesia di Kota Samarinda

Berdasarkan hasil penelitian yang dilakukan di GKII Kota Samarinda dengan jumlah populasi pemuda 727 orang, dan jumlah sampel yang dijadikan objek penelitian sebanyak 305 responden, maka didapati bahwa:

Tabel 1. Uji Pengaruh Secara Simultan (X1, X2, X3, X4 dan Y)

\begin{tabular}{|c|c|c|c|c|c|c|}
\hline \multicolumn{7}{|c|}{ ANOVA $^{a}$} \\
\hline & & $\begin{array}{l}\text { Sum of } \\
\text { Squares }\end{array}$ & df & Mean Square & $\mathrm{F}$ & Sig. \\
\hline \multirow[t]{3}{*}{1} & Regression & 734,605 & 4 & 183,651 & 146,723 &, $000^{\mathrm{b}}$ \\
\hline & Residual & 375,506 & 300 & 1,252 & & \\
\hline & Total & 1110,111 & 304 & & & \\
\hline
\end{tabular}

a. Dependent Variable: Kuantitas

b. Predictors: (Constant), Kelompok Kecil, Musik dan Multimedia, Komunitas, Olahraga

${ }^{23}$ Hengky Latan, Selva Temalagi, Analisis multivariate teknik dan aplikasi menggunakan program IBM SPSS 20.0 (Bandung: Alfabeta, 2013), 80. 2010), 128.

${ }^{24}$ Muhammad Arif Tiro, Analisis Korelasi dan Regresi (Makassar: Andira Publisher, 
Tabel 2. Uji Pengaruh Secara Simultan (X1, X2, X3, X4 dan Y)

Model Summary ${ }^{b}$

\begin{tabular}{|l|l|r|r|r|}
\hline Model & R & R Square & $\begin{array}{c}\text { Adjusted R } \\
\text { Square }\end{array}$ & $\begin{array}{c}\text { Std. Error of } \\
\text { the Estimate }\end{array}$ \\
\hline 1 &, $813^{\mathrm{a}}$ &, 662 &, 657 & 1,119 \\
\hline
\end{tabular}

a. Predictors: (Constant), Kelompok Kecil, Musik dan Multimedia,

Komunitas, Olahraga

b. Dependent Variable: Kuantitas

Tabel Anova di atas memberikan hasil bahwa tingkat signifikansi yang diperoleh sebesar $0,000<0,05$, hal ini berartii bahwa menolak Ho dan menerima Hl. Sehingga secara simultan varabel independen dalam penelitian ini (X1, X2, X3, X4) berpengaruh signifikan terhadap variabel dependen (Y). Sedangkan untuk mengetahui seberapa besar pengaruh yang diberikan variabel independen tersebut terhadap variabel Y terlihat pada koefisien determinasi yang terdapat dalam R Square tabel Model Summary.

Besarnya koefisien determinasi yang diperoleh adalah 0,662 atau $66,2 \%$ yang menandakan bahwa pengaruh semua variabel independen dalam penelitian ini sebesar 66,2\% terhadap Variabel dependen kuantitas, sedangkan sisanya sebesar 33,8\% dipengaruhi oleh faktor lain yang belum dikaji dalam penelitian ini.

Adapun model persamaan regresi linear berganda yang diperoleh untuk $Y$ adalah:

$\mathrm{Y}=\mathrm{Bo}+\mathrm{B} 1(\mathrm{Xl})+\mathrm{B} 2(\mathrm{X} 2)+\mathrm{B} 3(\mathrm{X} 3)+\mathrm{B} 4(\mathrm{X} 4)$

$\mathrm{Y}=0,195+0,089(\mathrm{Xl})+0,041(\mathrm{X} 2)+0,166(\mathrm{X} 3)+0,085(\mathrm{X} 4)$

Secara matematis persamaan di atas dapat dijelaskan dengan mengambil nilai-nilai yang terdapat pada tabel 15 uji tingkat signifikansi: Xl ke Y, X2 ke Y, X3 ke Y, dan X4 ke Y.

Tabel 3. Uji Pengaruh secara Simultan (X1, X2, X3, X4 dan Y)

Coefficients $^{a}$

\begin{tabular}{|c|c|c|c|c|c|c|}
\hline \multirow{2}{*}{\multicolumn{2}{|c|}{ Model }} & \multicolumn{2}{|c|}{ Unstandardized Coefficients } & \multirow{2}{*}{$\begin{array}{c}\begin{array}{c}\text { Standardized } \\
\text { Coefficients }\end{array} \\
\text { Beta } \\
\end{array}$} & \multirow[b]{2}{*}{$\mathrm{t}$} & \multirow[b]{2}{*}{ Sig. } \\
\hline & & $\mathrm{B}$ & Std. Error & & & \\
\hline \multirow[t]{5}{*}{1} & (Constant) & 195 &, 674 & &, 289 &, 773 \\
\hline & Musik dan Multimedia & 089 & 014 & ,269 & 6,398 &, 000 \\
\hline & Olahraga &, 041 & 014 & 134 & 2,883 &, 004 \\
\hline & Komunitas & , 166 & 018 & , 425 & 9,308 &, 000 \\
\hline & Kelompok Kecil &, 085 &, 020 & 183 & 4,186 &, 000 \\
\hline
\end{tabular}

a. Dependent Variable: Kuantitas

1) Bo $=0,195$, konstanta ini menandakan bahwa jika nilai variabel independen X1,X2, X3, dan X4 adalah 0, maka nilai Y adalah 0,195. Dengan kata lain bahwa kuantitas tanpa adanya musik dan multimedia, olahraga, komunitas, dan kelompok kecil sebesar 0,195. 
2) $\mathrm{Bl}=0,089$, koefisien regresi variabel $\mathrm{Xl}$ atau musik dan multimedia sebesar 0,089 artinya bahwa peningkatan satu persen variabel musik dan multimedia akan menyebabkan peningkatan kuantitas sebesar 0,089.

3) $B 2=0,041$, koefisien regresi variabel $X 2$ atau olahraga sebesar 0,041 artinya bahwa peningkatan satu persen variabel olahraga akan menyebabkan peningkatan kuantitas sebesar 0,041.

4) $B 3=0,166$, koefisien regresi variabel $X 3$ atau komunitas sebesar 0,182 artinya bahwa peningkatan satu persen variabel komunitas akan menyebabkan peningkatan kuantitas sebesar 0,166.

B4 =0,085, koefisien regresi variabel X4 atau kelompok kecil sebesar 0,085 artinya bahwa peningkatan satu persen variabel kelompok kecil akan menyebabkan peningkatan kuantitas sebesar 0,085.

\section{Kesimpulan}

Setelah melakukan analisis terhadap hasil perolehan data penelitian, maka dapat disimpulkan bahwa: Besarnya koefisien determinasi yang diperoleh dari uji pengaruh $\mathrm{X}$ total (pelayanan pemuda berbasis kontekstual) ke Y2 (pertumbuhan gereja secara kuantitas) adalah 0,662 atau $66,2 \%$ yang menandakan bahwa pengaruh semua variabel independen dalam penelitian ini sebesar $66,2 \%$ terhadap variabel dependen kuantitas, sedangkan sisanya sebesar 33,8\% dipengaruhi oleh faktor lain yang belum dikaji dalam penelitian ini. Berdasarkan hasil penelitian, kegiatan olahraga memungkinkan para pemuda untuk mendapatkan teman baru melalui kegiatan olahraga. Kegiatan olahraga membuat mereka dapat bertemu dengan begitu banyak pemuda lain yang mengunjungi tempat olahraga karena kebutuhan yang sama sebagai pengguna lapangan ataupun penggemar olahraga tertentu. Hal tersebut membuat mereka tidak dapat menghindari kontak dengan teman-teman baru, serta membangun komunikasi dengan teman-teman tersebut.

Demikian juga dengan komunitas-komunitas anak muda lainnya, hal tersebut memungkinkan anak-anak muda dapat bertemu secara intensif setiap minggu dan menghabiskan waktu secara bersama-sama setiap minggunya. Hal ini menjadi peluang bagi pemuda gereja untuk dapat mengundang atau mengajak teman olahraga atau komunitas mereka untuk dapat bergaung dalam ibadah atau kegiatan pemuda yang dilaksanakan di gereja. Oleh sebab itu, hal ini memberi pengaruh positif terhadap pertumbuhan secara kuantitas. Adanya fasilitas musik dan sarana multimedia yang memadai di gereja juga menambah minat mereka yang datang walapun untuk pertama kalinya mungkin hanya karena memenuhi undangan sahabat mereka. Setelah memiliki lebih banyak teman di gereja, mereka juga akan diajak bergabung dalam kelompok kecil yang terdekat dengan tempat tinggal mereka atau kelompok kecil di mana 
rekan-rekan komunitas atau teman olahraga mereka menjadi anggota. Hal inilah yang membuat terjadinya pengaruh yang signifikan dari indikatorindikator X1, X2, X3, dan X4 terhadap Y2 (pertumbuhan kuantitas).

\section{Kepustakaan}

Benson, Warren S., Mark Senter III. Pedoman Lengkap Untuk Pelayanan Kaum Muda. Bandung: Kalam Hidup, 1999.

Bevans, Stephen B. Model-model Teologi Kontekstualisasi. Maumere: Ledalero, 2002.

Churchill, Dana. Cultural Contextualization Recommendations for Latino Youth

Programs. Master of Arts, International Community Development. South Africa: Northwest University, 2016.

https://archives.northwestu.edu/bitstream/handle/nu/25l77/chur chill_dana_icd_2016.pdf? sequence=1.

Edwards, David. Dkk. Everything Twentys. Illinois: Tyndale house publishers, $7^{\text {th }}$ edition 2011.

Churchill, Dana. Cultural Contextualization Recommendations for Latino Youth Programs. Master of Arts, International Community Development. South Africa: Northwest University, 2016.

https://archives.northwestu.edu/bitstream/handle/nu/25177/churc hill_dana_icd_2016.pdf?sequence=1.

Egbo, N. M., and D. C. Bartholomew. "Forecasting Students' Enrollment Using Neural Networks and Ordinary Least Squares Regression Models." Journal of Advanced Statistics 3, no. 4 (December 1, 2018): $45-57$.

Fields, Doug. Purpose Driven Youth Ministry: 9 Landasan Penting Bagi Pertumbuhan yang Sehat. Malang: Gandum Mas, 2014.

Latan, H., Selva Temalagi. Analisis Multivariate. Bandung: Alfabeta, 2013.

Manna, Michael Andrew. "The Indigenous Contextialization Model Ukrainian Youth Ministers' Adaptation of Practical Theological Education." Biola University, 2015.

http://www.youthdiscipler.com/uploads/8/0/1/9/8019280/manna__the_indigenous_contextualization_model.pdf.

Moreau, A. Scott. Contextualization in World Missions. Grand Rapids USA: Kregel Publication, 2012.

Naafs, Suzanne dan Ben White. "Generasi Antara: Refleksi tentang Studi Pemuda Indonesia." Jurnal Studi Pemuda I, No. 2 (September 2012):89-106.

https:/journal.ugm.ac.id/jurnalpemuda/article/viewFile/32063/193 87. 
Thayer, Joseph H. Thayer's Greek-English Lexicon of the New Testament. Massachusetts: Hendrikckson Publishers, eighth printing 2007.

Tiro, Muhammad Arif. Analisis Korelasi dan Regresi. Makassar: Andira Publisher, edisi ketiga 2010.

Vredenbregt, J. Metode dan Teknik Penelitian Masyarakat. Jakarta: Gramedia, 1984.

Walker, Joyce A. "Intentional Youth Programs: Taking Theory to Practice." New Directions for Youth Development (2006): 75-92.

Widyanto, Aloysius Bram. "Pemuda Dalam Perubahan Sosial." Jurnal Historia Vitae 24, No. 2 (Oktober 2010): 153-162.

https://www.usd.ac.id/lembaga/lppm/fll3/Jurnal\%20Historia\%20 Vitae/vol24no2oktober2010/PEMUDA\%20DALAM\%20PERUBA HAN\%20SOSIAL\%20bram\%20widyanto.pdf 